\title{
SEARCH FOR ALTERNATIVE SOURCES OF NATURAL PLANT ANTIOXIDANTS FOR FOOD INDUSTRY
}

\author{
Nadezhda V. Kupaeva ${ }^{1,2 *}$, Elena A. Kotenkova ${ }^{1}$ \\ ${ }^{1}$ V.M. Gorbatov Federal Research Center for Food Systems of Russian Academy of Sciences, Moscow, Russia \\ ${ }^{2}$ Dmitry Mendeleev University of Chemical Technology of Russia, Moscow, Russia
}

\section{KEY WORDS:}

plant antioxidant, total antioxidant capacity, ORAC, FRAP, efficient environmental management, waste processing

\begin{abstract}
According to the data of the Food and Agriculture Organization of the United Nations, global food losses are about one third of their total output, mainly due to spoilage. Therefore, a search for safe methods of shelf life extension is an important task, especially for products for specialized nutrition. According to literature data, natural antioxidants can be alternative to existing preservatives due to its ability to inhibit oxidation of the main nutrients. Pulp, seeds and peel of quince, apple «Simirenko», feijoa, persimmon, Jerusalem artichoke, white, red and yellow onion were objects of the study. The total antioxidant capacity was determined by Oxygen Radical Absorbance Capacity (ORAC) and Ferric Reducing Antioxidant Power (FRAP) methods and expressed in $\mu \mathrm{mol}$ equiv. Trolox / $\mathrm{g}$ of sample and $\mu$ mol equiv. Dihydroquercetin / $g$ of sample. It was noticed that peels demonstrated higher antioxidant activity, and red onion husk possessed the highest value, which was $722.8 \pm 13.9 \mu \mathrm{mol}$ equiv. Dihydroquercetin / $\mathrm{g}$ of sample and $3357.5 \pm 42.2 \mu \mathrm{mol}$ equiv. Trolox / $\mathrm{g}$ of sample. It was shown that the use of fruit and vegetable wastes is promising for production of food-grade antioxidants. In addition, the results of the research could facilitate stimulation of rational and efficient environmental management.
\end{abstract}

\section{Introduction}

In the developed countries, an amount of food waste increases every year. According to Food and Agriculture Organization of the United Nations (FAO) data, one third of all food produced in the world is either lost or wasted, which is about 1.3 billion tons per year [1]. In this connection, the industry faces an emergent need for improvement of existing or development of new approaches to shelf life extension. Nowadays, there are several main approaches: technological, physical and chemical treatment [2], among which the latter could be potentially dangerous to human health. For example, food preservatives include E200-E299 and some of them are forbidden for the use in several countries depending on the legislation [3,4]. Synthetic preservatives are in demand due to cost-efficiency; therefore, their use is widespread [5,6].

Nowadays, a search for alternative sources of natural preservatives is relevant, because negative effect of synthetic preservatives on health was proven [7,8]. Moreover, a demand for healthy foods is growing and an assortment of functional and specialized products is increasing, including foods for breastfeeding and pregnant women, children and adolescents. Thus, plant antioxidants could be an alternative source of natural preserving agents. It is known that natural antioxidants (AO) in the composition of plant extracts and in a form of mono-substances are widely used both as natural preservatives and as functional additives. The antioxidants with the proved positive effect include dihydroquercetin, tocopherol, vitamin $C$ and others $[9,10,11]$.

In this research, the antioxidant potential of several plants including their pulp, peel and seeds was determined. The antioxidant potential of the samples was determined by Oxygen Radical Absorbance Capacity (ORAC) and Ferric Reducing Antioxidant Power (FRAP) methods.

\section{Materials and methods}

Guince, apple «Simirenko», feijoa, persimmon, Jerusalem artichoke, white, red and yellow onion were objects of the study. Raw materials were bought in the store «VkusVill». For more detailed analysis, their peel, pulp and seeds were analyzed separately depending on the plant. The list of samples is given in Table 1.
Table 1

The list of plant samples

\begin{tabular}{llcccc}
\hline № & Objects & $\begin{array}{c}\text { Peel } \\
\text { (top } \\
\text { layer) }\end{array}$ & Peel & Pulp & Seeds \\
\hline 1 & Quince (harvest of 2018) & - & 1.1 & 1.2 & 1.3 \\
\hline 2 & Apple («Simirenko», harvest of 2018) & - & 2.1 & 2.2 & 2.3 \\
\hline 3 & Feijoa (Azerbaijan, harvest of 2018) & - & 3.1 & 3.2 & $3.3^{*}$ \\
\hline & $\begin{array}{l}\text { Persimmon («Shish Burun», } \\
\text { Azerbaijan) }\end{array}$ & - & 4.1 & 4.2 & - \\
\hline 5 & Jerusalem artichoke & - & 5.1 & 5.2 & - \\
\hline 6 & Yellow onion & 6.1 & 6.2 & 6.3 & - \\
\hline 7 & White onion & - & 7.1 & 7.2 & - \\
\hline 8 & Red onion & - & 8.1 & 8.2 & - \\
\hline "pulp with seeds & & & & \\
\hline
\end{tabular}

Aqueous extracts were prepared for analysis. $1 \mathrm{~g}$ of a minced sample was mixed with $50 \mathrm{ml}$ of boiled distilled water and infused for $15 \mathrm{~min}$ in a closed container with periodic mixing. After that, extracts were filtered through filter paper. The extract of sample 1.3 was centrifuged at $3500 \mathrm{G}$ for 5 min in SIGMA 3 30KS centrifuge («Sigma Laborzentrifugen», Germany). The obtained water extracts were stored at $4^{\circ} \mathrm{C}$ not more than 3 days.

Total antioxidant capacity (TAC) of extracts was determined by fluorescent ORAC method and expressed in $\mu$ mol equiv. Trolox / $g$ of sample. The measurements were carried out on Fluoroskan Ascent FL (TermoLabsystems, Finland) with the use of black 96-well plates by the method [12] in our own modification [13].

The total antioxidant capacity of extracts was determined by the photometric FRAP method on a spectrophotometer SF-2000 (OCB «Spectr», Russia) using the methodology [14] in our own modification [13]. Results were expressed in $\mu$ mol equiv. Dihydroquercetin / $\mathrm{g}$ of sample.

STATISTICA 10.0 software was used in this study for the statistical analyses. The results were calculated as «middle value \pm standard error» $(\mathrm{M} \pm \mathrm{SE})$. Significant differences were tested by one-way ANOVA, followed by the Tukey test. Differences with P-values less than 0.05 were considered as statistically significant. 


\section{Results and discussion}

The indicators of the antioxidant potential of the selected samples were analyzed by the ORAC method (determination of antioxidants absorbance capacity in regard to oxygen radicals (ROO• and RO•)), and by the FRAP method (determination of total antioxidant capacity of a sample). The antioxidant potential was measured in difference parts of the selected samples, such as peel, pulp and seeds. The results are presented in Table 2.

Results of determination of the antioxidant capacity of the selected samples by the ORAC and FRAP methods

\begin{tabular}{|c|c|c|c|}
\hline № & $\begin{array}{l}\text { Part of } \\
\text { samples }\end{array}$ & $\begin{array}{l}\text { FRAP ( } \mu \text { mol equiv. } \\
\text { Dihydroquercetin / } g \\
\text { of sample) }\end{array}$ & $\begin{array}{c}\text { ORAC } \\
\text { ( } \mu \text { mol equiv. } \\
\text { Trolox / } \mathrm{g} \text { of sample) }\end{array}$ \\
\hline \multicolumn{4}{|c|}{ 1. Quince (harvest of 2018) } \\
\hline 1.1 & Peel & $232.5 \pm 8.5^{\mathrm{a}}$ & $918.7 \pm 16.4$ \\
\hline 1.2 & Pulp & $15.8 \pm 1.5^{\mathrm{b}, \mathrm{c}}$ & BDL \\
\hline 1.3 & Seeds & $3.1 \pm 0.2^{\mathrm{b}, \mathrm{d}}$ & BDL \\
\hline
\end{tabular}

2. Apple («Simirenko», harvest of 2018)

\begin{tabular}{lccc}
\hline 2.1 & Peel & $119.5 \pm 4.8^{\mathrm{a}}$ & $541.3^{2} \pm 29.3^{\mathrm{a}}$ \\
\hline 2.2 & Pulp & $20.3 \pm 1.4^{\mathrm{b}, \mathrm{c}}$ & BDL \\
\hline 2.3 & Seeds & $63.0 \pm 0.8^{\mathrm{b}, \mathrm{d}}$ & $113.7 \pm 15.4^{\mathrm{b}}$ \\
& & 3. Feijoa (Azerbaijan, harvest of 2018) \\
\hline 3.1 & Peel & $302.5^{ \pm} \pm 8.8^{\mathrm{a}}$ & $553.1 \pm 4.7^{\mathrm{a}}$ \\
\hline 3.2 & Pulp & $145.2^{\mathrm{a}} \pm 5.2^{\mathrm{b} . \mathrm{c}}$ & $160.3 \pm 27.1^{\mathrm{b}, \mathrm{c}}$ \\
3.3 & Pulp with seeds & $45.0 \pm 2.0^{\mathrm{b}, \mathrm{d}}$ & $42.6 \pm 8.3^{\mathrm{b}, \mathrm{d}}$
\end{tabular}

4. Persimmon («Shish Burun», Azerbaijan)

\begin{tabular}{|c|c|c|c|}
\hline 4.1 & Peel & $25.1 \pm 3.2^{\mathrm{b}}$ & $19.3 \pm 4.5$ \\
\hline 4.2 & Pulp & $121.8 \pm 6.6^{\mathrm{a}}$ & BDL \\
\hline \multicolumn{4}{|c|}{ 5. Jerusalem artichoke } \\
\hline 5.1 & Peel & $32.0 \pm 4.2^{\mathrm{a}}$ & $305.7 \pm 10.3^{\mathrm{a}}$ \\
\hline 5.2 & Pulp & $0.2 \pm 0.00^{\mathrm{b}}$ & $5.3 \pm 1.9^{b}$ \\
\hline \multicolumn{4}{|c|}{ 6. Yellow onion } \\
\hline 6.1 & $\begin{array}{c}\text { Peel } \\
\text { (top layer) }\end{array}$ & $437.0 \pm 10.5^{\mathrm{a}}$ & $2484.2 \pm 49.2^{\mathrm{a}}$ \\
\hline 6.2 & Peel & $107.9 \pm 5.7^{b, c}$ & $779.3 \pm 16.5^{b}$ \\
\hline 6.3 & Pulp & $0.7 \pm 0.0^{6, \mathrm{r}}$ & BDL \\
\hline \multicolumn{4}{|c|}{ 7. White onion } \\
\hline 7.1 & Peel & $3.2 \pm 0.1^{\mathrm{a}}$ & $33.4 \pm 7.8$ \\
\hline 7.2 & Pulp & $0.3 \pm 0.0^{\mathrm{b}}$ & BDL \\
\hline \multicolumn{4}{|c|}{ 8. Crimean onion } \\
\hline 8.1 & Peel & $722.8 \pm 13.9^{\mathrm{a}}$ & $3357.5 \pm 42.2$ \\
\hline 8.2 & Pulp & $2.9 \pm 0.2^{b}$ & BDL \\
\hline
\end{tabular}

* - BDL - below detection limit. a-b, c-d - significant difference between parts of the experimental samples $(\mathrm{P}<0.05)$

It was shown that peels of the plant samples demonstrated the highest antioxidant activity. For example, for quince peel, the antioxidant activity determined by the FRAP method was $232.5 \pm 8.5 \mu \mathrm{mol}$ equiv. Dihydroquercetin / $\mathrm{g}$ of sample, which was higher than the value of pulp and seeds by 27.4 times $(\mathrm{P}<0.05)$ and 75.0 times $(\mathrm{P}<0.05)$, respectively. The absorbance capacity of antioxidants determined by the ORAC method was $918.7 \pm 16.4$ $\mu$ mol equiv. Trolox / $g$ of sample, while in pulp and seeds it was below detection limit.

The antioxidant activity of apple peel determined by the FRAP method was $119.5 \pm 4.8 \mu \mathrm{mol}$ equiv. Dihydroquercetin / $\mathrm{g}$ of sample and exceeded the value pulp and seeds by 5.9 times $(\mathrm{P}<0.05)$ and 1.9 times $(\mathrm{P}<0.05)$, respectively. The absorbance capacity of antioxidants determined by the ORAC method was
$541.3 \pm 29.3 \mu$ mol equiv. Trolox / $\mathrm{g}$ of sample, while in pulp it was below detection limit and in seeds it was $113.7 \pm 15.4 \mu \mathrm{mol}$ equiv. Trolox / $g$ of sample, which was lower than the value of peel by 4.8 times $(\mathrm{P}<0.05)$.

The antioxidant activity of feijoa peel determined by the FRAP method was $302.5 \pm 8.8 \mu$ mol equiv. Dihydroquercetin / $g$ of sample and exceeded the value of pulp and seeds by 2.1 times $(\mathrm{P}<0.05)$ and 6.7 times $(\mathrm{P}<0.05)$, respectively. The absorbance capacity of antioxidants determined by the ORAC method was $553.1 \pm 4.7 \mu \mathrm{mol}$ equiv. Trolox / $g$ of sample and exceeded the value of pulp and seeds by 3.5 times $(\mathrm{P}<0.05)$ and 13.0 times $(\mathrm{P}<0.05)$, respectively.

The antioxidant activity of Jerusalem artichoke peel determined by the FRAP method was 32.0 $\pm 4.2 \mu$ mol equiv. Dihydroquercetin / $\mathrm{g}$ of sample and exceeded the value of pulp by 160 times $(\mathrm{P}<0.05)$. The absorbance capacity of antioxidants determined by the ORAC method was $305.7 \pm 10.3 \mu \mathrm{mol}$ equiv. Trolox / $\mathrm{g}$ of sample and exceeded the value of pulp by 57.7 times $(\mathrm{P}<0.05)$.

The inverse trend was observed regarding persimmon. It was shown that the antioxidant capacity of pulp determined by the FRAP method was $121.8 \pm 6.6 \mu \mathrm{mol}$ equiv. Dihydroquercetin / $\mathrm{g}$ of sample and exceeded the value of peel by 4.9 times $(\mathrm{P}<0.05)$. On the contrary, the absorbance capacity of antioxidants determined in pulp by the ORAC method was below detection limit, while in peel it was $19.3 \pm 4.5 \mu \mathrm{mol}$ equiv. Trolox / $\mathrm{g}$ of sample.

The antioxidant activity of the top layer of yellow onion peel determined by the FRAP method was $437.0 \pm 10.5 \mu$ mol equiv. Dihydroquercetin / $g$ of sample and exceeded the value of lower layer of peel and pulp by 4.1 times $(\mathrm{P}<0.05)$ and 624.3 times $(\mathrm{P}<0.05)$, respectively. The absorbance capacity of antioxidants determined by the ORAC method was $2484.2 \pm 49.2 \mu$ mol equiv. Trolox / $g$ of sample, in pulp it was below detection limit and in the lower layer of peel was equal to $779.3 \pm 16.5 \mu \mathrm{mol}$ equiv. Trolox / $\mathrm{g}$ of sample, which was lower than the value in the top layer of peel by 3.2 times $(\mathrm{P}<0.05)$.

The antioxidant activity of white onion peel determined by the FRAP method was $3.2 \pm 0.1 \mu \mathrm{mol}$ equiv. Dihydroquercetin / $\mathrm{g}$ of sample and exceeded the value of pulp by 10.7 times $(\mathrm{P}<0.05)$. The absorbance capacity of antioxidants determined by the ORAC method was $33.4 \pm 7.8 \mu$ mol equiv. Trolox / $\mathrm{g}$ of sample, in pulp it was below detection limit.

The antioxidant activity of red onion peel determined by the FRAP method was $722.8 \pm 13.9 \mu \mathrm{mol}$ equiv. Dihydroquercetin / $g$ of sample and exceeded the value of pulp by 249.2 times $(\mathrm{P}<0.05)$. The absorbance capacity of antioxidants determined by the ORAC method was $3357.5 \pm 42.2 \mu$ mol equiv. Trolox / $g$ of sample, in pulp it was below detection limit.

The interspecies differences were found concerning onion samples. For example, the maximum antioxidant activity determined by the FRAP method and absorbance capacity of antioxidants determined by the ORAC method were found in red onion peel and were equal to $722.8 \pm 13.9 \mu \mathrm{mol}$ equiv. Dihydroquercetin / $\mathrm{g}$ of sample and $3357.5 \pm 42.2 \mu \mathrm{mol}$ equiv. Trolox / $\mathrm{g}$ of sample, which was higher than the value yellow onion by $65.4 \%(\mathrm{P}<0.05)$ and $35.2 \%(\mathrm{P}<0.05)$, respectively. The detected values in white onion were incommensurably small.

It is known that fruit and vegetable processing generates a huge percentage of plant waste [15]. Peel and husk is one of the main wastes and is a potential perspective source of antioxidants. Obtained results displayed that peels of plant raw materials were characterized by the highest antioxidant capacity. Among the obvious advantages of using such type of waste is low cost of the proposed approach and stimulation of complex processing and rational environmental management. Among plant raw materials, onion, quince and feijoa are the most promising sources of antioxidants, especially their peels.The antioxidant activity of peels of quince, feijoa, bulb and red onion, determined by the FRAP 
method was $232.5 \pm 8.5,302.5 \pm 8.8,437.0 \pm 10.5$ and $722.8 \pm 13.9$ $\mu \mathrm{mol}$ equiv. Dihydroquercetin / $\mathrm{g}$ of sample, respectively; the absorbance capacity of antioxidants determined by the ORAC method was $918.7 \pm 16.4,553.1 \pm 4.7,2484.2 \pm 49.2$ and $3357.5 \pm 42.2$ $\mu \mathrm{mol}$ equiv. Trolox / $\mathrm{g}$ of sample, respectively.

\section{Conclusion}

The interspecies differences were determined concerning onion samples. Red onion peel displayed the maximum antioxidant activity determined by the FRAP method and absorbance capacity of antioxidants determined by the ORAC method equaled to $722.8 \pm 13.9$ umol equiv. Dihydroquercetin / $\mathrm{g}$ of sample and $3357.5 \pm 42.2 \mu \mathrm{mol}$ equiv. Trolox / $\mathrm{g}$ of sample, respectively, which was higher than the value of yellow onion by $65.4 \%(\mathrm{P}<0.05)$ and $35.2 \%(P<0.05)$, respectively. The detected values in white onion were incommensurably small.

The obtained data confirmed the efficiency of use waste of fruit and vegetable industry as a source of natural antioxidants, which are safe and are in demand as food-grade preservatives. In addition, this raw material is easily available and cost-effective, and facilitates an improvement of ecological situation due to reduction of waste volumes by their processing.

\section{REFERENCES}

1. Food Loss and Food Waste. [Electronic resource: http://www.fao.org/ food-loss-and-food-waste/ru/ Access date 19.08.2019] (in Russian)

2. Lukinova, E.A., Kotenkova, E.A., Makarenko, A.N. (2017). Antimicrobial substances: an alternative approach to the extension of shelf life. Theory and practice of meat processing, 2(3), 4-20. DOI: 10.21323/2414438X-2017-2-3-4-20 (in Russian)

3. Esimbekova, E.N., Asanova, A.A., Deeva, A.A., Kratasyuk, V.A. (2017). Inhibition effect of food preservatives on endoproteinases. Food Chemistry, 235, 294-297. DOI: 10.1016/j.foodchem.2017.05.059

4. Kalpana, V.N., Rajeswari, V.D. (2019). Preservatives in Beverages: Perception and Needs. Chapter 1 in the book Preservatives and Preservation Approaches in Beverages, 15, 1-30. ISBN 9780128166857

5. Mohammadzadeh-Aghdash, H., Akbari, N., Esazadeh, K., Ezzati Nazhad Dolatabadi, J. (2019). Molecular and technical aspects on the interaction of serum albumin with multifunctional food preservatives. Food Chemistry, 393, 491-498. DOI: 10.1016/i.foodchem.2019.04.119

6. Onishchuk, D.I., Zhukov, V.V. (2012). The use of food addition as additives in population nutrition. Bulletin of medical Internet-conferences, 2(2), 67. (in Russian)

7. Titova, N.D. (2008). Food addition as alimentary allergens. Immunopathology, Allergology, Infectology., 2, 41-46. (in Russian)

8. Blagoveshchenskaya, D.B., Merzlyakov, A.S. (2011). Studying toxic properties of widespread modern preservatives. Journal of New Medical Technologies, 18(2), 501-502. (in Russian)
9. Konovalov, K.L., Shulbaeva, M.T. (2008). Vegetative food composites for manufacturing of combined products. Food Industry, 7, 8-12. (in Russian)

10. Pogosyan, D.G., Gavryushyna, I.V., Shyshkina, T.V. (2014). Application of dehydroquercitin for curds production. Dairy Industry, 7, 62-63. (in Russian)

11. Reshetnik, E.I. (2011). Substantiation and development of the food production technology with the use of dihydroquercetin. Agricultural Journal in the Far East Federal District,1(1),130-132. (in Russian)

12. SP\&A Application Laboratory (2016) Determination of Antioxidant Capacity on the Thermo Scientific Varioskan LUX Multimode Reader Thermo Fisher Scientific [Electronic resource: https://assets.thermofisher. com/TFS-Assets/LED/Application-Notes/Antioxidant-Capacity-AN-VarioskanLUX-ORAC-EN.pdf/ Access date 05.08.2019]

13. Kupaeva, N.V. (2018). Determination of general antioxidant capacity of vegetable food additives. Proceedings of the 12th International scientificpractical conference of young scientists and specialists of organizations in the sphere of agricultural sciences, 183-189. (in Russian)

14. Gimadieva, A.R., Khazimullina, Yu.Z., Belaya, E.A., Zimin, Yu.S., Abdrakhmanov I.B., Mustafin, A.G. (2015). Express evaluation of antioxidant activity of uracil derivatives. Biomedical Chemistry, 61(6), 765-769. DOI: 10.18097/PBMC20156106765 (in Russian)

15. Cleaning of fruit and vegetable raw material before drying. [Electronic resource: http://www.activestudy.info/ochistka-plodoovoshhnogo-syryapered-sushkoj Access date 19.08.2019] (in Russian)

\section{AUTHOR INFORMATION}

Nadezhda V. Kupaeva - bachelor of chemistry, student of Dmitry Mendeleev University of Chemical Technology of Russia, laboratory assistant of Experimental clinic - research laboratory of biologically active substances of an animal origin. V.M. Gorbatov Federal Research Center for Food Systems of Russian Academy of Sciences, 109316, Moscow, Talalikhina str., 26. Tel.: +7-966-359-19-00 E-mail: NVkupaeva@yandex.ru *corresponding author

Elena A. Kotenkova - candidate of technical sciences, research scientist of Experimental clinic - research laboratory of biologically active substances of an animal origin. V.M. Gorbatov Federal Research Center for Food Systems of Russian Academy of Sciences,

109316, Moscow, Talalikhina str., 26. Tel.: +7-495-676-92-11, E-mail: lazovlena92@yandex.ru

Authors are equally relevant to the writing of the manuscript, and equally responsible for plagiarism

The authors declare no conflict of interest

Received 20.07.2019 Accepted in revised 30.08.2019 Accepted for publication 10.09.2019 